\title{
Pelatihan Pengumpulan Sampah Laut Kepada Pengunjung Pantai Pangandaran
}

\section{Citizen-Based Marine Debris Collection Training: Study case in Pangandaran}

\author{
Izza Mahdiana Apriliani ${ }^{1}$, Noir P Purba ${ }^{2}$, Lantun Paradhita Dewanti ${ }^{1}$, Heti Herawati ${ }^{1}$, Ibnu Faizal ${ }^{2}$
}

\section{* Korespondensi Penulis:}

\section{Izza Mahdiana Apriliani}

E-mail: izza.mahdiana@unpad.ac.id

${ }^{1}$ Departemen Perikanan, Fakultas Perikanan dan Ilmu Kelautan,

Universitas Padjadjaran, Sumedang

${ }^{2}$ Departemen Ilmu Kelautan, Fakultas

Perikanan dan Ilmu Kelautan,

Universitas Padjadjaran, Sumedang

Submitted Jan 26, 2021.

Revised Jan 29, 2021.

Accepted Jan 31, 2021.

\begin{abstract}
Continuous and global monitoring of waste is needed to reduce its impact on water. One of them is monitoring garbage on Pangandaran Beach which is one of the mainstay tourist objects in West Java. A large number of residents and tourists causes frequent waste products that are discarded and that come from other areas. This activity aims to provide knowledge to Pangandaran Beach visitors and the community in increasing awareness of coastal marine waste. The target audience is the community and Pangandaran beach tourists. The activity was carried out using a participatory method, which provides insight into how to collect waste on a simple but accountable scientific basis. Based on the overall training activities, both in the form of lectures/discussions and beach clean-up actions, it can be concluded that the target audience understands the importance of protecting the coastal and marine environment. As well as an increase in the skills of the target audience in understanding the world's efforts through the ICC (International Coastal Clean-Up) organization with the grouping of waste in it. Participants can also apply for the form because it is easy to fill out. On the other hand, it is necessary to translate the form into Indonesian so that it can be used by all levels of society.
\end{abstract}

Keywords: Coastal Environment, Marine Debris, Tourists, Plastics

\begin{abstract}
Abstrak
Monitoring sampah secara kontinu dan global diperlukan untuk mengurangi dampaknya di perairan. Salah satunya monitoring sampah di Pantai Pangandaran yang merupakan salah satu objek wisata andalan di Jawa Barat. Banyaknya jumlah penduduk dan wisatawan menyebabkan sering terdapat sampah hasil buangan dan yang berasal dari daerah lain. Kegiatan ini bertujuan untuk memberikan pengetahuan kepada pengunjung Pantai Pangandaran maupun masyarakat dalam meningkatkan kepedulian terhadap sampah pesisir laut. Khalayak sasaran berupa masyarakat dan wisatawan pantai Pangandaran. Kegiatan dilakukan dengan metode partisipatori yakni memberikan wawasan bagaimana mengumpulkan sampah dengan basis ilmiah sederhana namun dapat dipertanggungjawabkan. Berdasarkan kegiatan pelatihan secara keseluruhan, baik dalam bentuk ceramah/diskusi maupun aksi bersih pantai dapat disimpulkan bahwa khalayak sasaran memahami pentingnya menjaga lingkungan pesisir dan laut. Serta adanya peningkatan skill khalayak sasaran dalam memahami upaya dunia melalui organisasi ICC (International Coastal Clean Up) dengan pengelompokkan sampah yang ada di dalamnya. Para peserta juga dapat mengaplikasikan form tersebut dikarenakan kemudahan untuk mengisi. Dilain hal, diperlukan penerjemahan form tersebut kedalam Bahasa Indonesia agar dapat digunakan oleh semua lapisan masyarakat.
\end{abstract}

Kata Kunci: Lingkungan Pesisir, Sampah Laut, Wisatawan, Plastik 


\section{Pendahuluan}

Pantai Pangandaran adalah salah satu objek wisata andalan di Jawa Barat. Pantai ini terletak di wilayah selatan dan berbatasan langsung dengan samudera Hindia. Lokasi ini cukup mengundang wisatawan domestik maupun mancanegara. Adanya potensi wisata ini menjadikan Kecamatan Pangandaran memiliki kepadatan penduduk tertinggi di Kabupaten Pangandaran. Sebanyak 15,57\% penduduk bertempat tinggal di wilayah ini dikarenakan faktor perekonomian (Pemda Kabupaten Pangandaran, 2016). Hal ini dapat menunjukkan sebuah potret potensi kawasan pesisir yang menjanjikan untuk dikelola dan mampu meningkatkan taraf hidup penduduk Kabupaten Pangandaran.

Banyaknya jumlah penduduk dan wisatawan akan membawa dampak lingkungan. Dampak lingkungan yang muncul diantaranya berupa pencemaran wilayah pesisir Pangandaran. Pencemaran lingkungan atau degradasi lingkungan yang sering muncul di daerah wisata pantai yaitu permasalahan sampah. Berdasarkan Hutabarat \& Evans (1985) menyampaikan beberapa pencemar pesisir dan lautan yang harus diwaspadai, diantaranya adalah pencemaran minyak, pencemaran logam berat, pestisida dan sampah. Perlu dilakukan berbagai upaya dalam menjaga kondisi lingkungan di daerah pesisir pantai untuk tetap mempertahankan kondisi ekosistemnya. Jika degradasi lingkungan terus menerus terjadi, maka akan berdampak pada pada kerusakan organisme yang hidup di daerah pesisir pantai tersebut (Hutabarat \& Evans, 1985). Seperti yang diketahui bahwa penduduk di wilayah ini terkonsentrasi di pantai dan disekitar sungai. Dalam hal ini akumulasi sampah dapat terbawa oleh sungai, langsung dibuang oleh wisatawan dan penduduk, serta oleh faktor oseanografi.

Berdasarkan hasil kajian yang dilakukan terkait sampah laut telah dilakukan di beberapa lokasi seperti di utara Jawa Barat (Pangestu et al., 2016), di pantai pulau Seribu (Purba et al., 2017; Maharani et al., 2018), kolom air di Nusa Tenggara (Hiwari et al., 2019), dan estuari DKI Jakarta (Rachmat et al., 2019). Sumber sampah ini dapat berasal dari berbagai lokasi seperti sungai, terbawa angin dan arus, atau buangan langsung. Terdapat dua jenis sampah yang mengotori pantai, yaitu sampah dari aktivitas wisata dan sampah bawaan dari laut (Darwati, 2019). Menurut Purba et al. (2018) yang telah mengkaji sampah makro di Pantai Pangandaran menemukan bahwa sampah yang terakumulasi di pantai bersumber dari turis, nelayan, dan sampah kiriman.

Menurut Darwati (2019) pengelolaan sampah dikawasan pesisir masih belum berjalan optimal. Salah satu bentuk upaya yang diharapkan dapat mendukung kebersihan pesisir adalah adanya upaya pro-aktif dari elemen masyarakat maupun wisatawan yang mengunjungi wilayah pantai. Mengingat pentingnya penanganan sampah di kawasan pantai diperlukan pengolahan sampah yang terpadu. Sistem pengolahan sampah terpadu harus disesuaikan dengan komposisi dari sampah di pantai, baik dari aktivitas wisata maupun sampah bawaan laut. Oleh karena itu, perlu dilakukan pengukuran lapangan berupa timbulan dan komposisi sampah di kawasan wisata pantai (Darwati, 2019). Selain itu, diperlukan monitoring secara global yang melibatkan berbagai komunitas, masyarakat, dan stakeholder agar pengelolaan sampah dapat tercapai.

Pengukuran timbunan dan komposisi sampah selaras dengan aksi yang dilakukan di kancah internasional dalam menjaga lingkungan pesisir ini. Berdasarkan Apriliani et al. (2017) Ocean Conservacy merupakan salah satu lembaga internasional yang rutin dalam memberikan aksi bersih pantai (coastal cleanup). Lembaga ini melakukan standarisasi terhadap sampah yang ditemukan di pesisir, danau dan laut serta melakukan analisis terhadap hasil tersebut. Adanya lembaga tersebut membuka peluang untuk mengedukasi masyarakat maupun pengunjung wisata. Dari pengalaman simulasi yang telah dilakukan kepada mahasiswa, bahwa form ini dapat diaplikasikan untuk masyarakat umum dan pemula. Edukasi tersebut bertujuan agar masyarakat maupun wisatawan perduli terhadap kebersihan lingkungan pesisir. Dengan demikian, kegiatan pengabdian ini bertujuan untuk memberikan pengetahuan kepada pengunjung Pantai Pangandaran maupun masyarakat dalam meningkatkan kepedulian terhadap sampah pesisir laut.

\section{Materi dan Metode Pelaksanaan}

Ruang lingkup materi yang disampaikan pada kegiatan ini berupa informasi sumber pencemar di laut dan upaya pengumpulan sampah di pesisir pantai Pangandaran. Adanya pemberian materi/informasi sumber pencemar di laut 
merupakan salah satu upaya untuk memberitahukan kepada khalayak sasaran mengenai pentingnya untuk menjaga kebersihan lingkungan pantai. Khalayak sasaran dilibatkan dalam proses pengumpulan sampah laut yang berada di sepanjang pantai tersebut.

Metode yang digunakan dalam kegiatan ini yaitu metode survey dengan teknik komunikasi persuasif-edukatif. Berdasarkan Saimama \& Noviansyah (2020), informasi persuasif memiliki pengertian bahwa informasi tersebut umumnya akan berisi pesan ajakan bagi penerima pesan, sedangkan informasi dengan sifat edukatif akan memberikan pengetahuan baru bagi siapa saja yang mendapatkannya. Teknik ini diharapkan dapat meningkatkan kesadaran lingkungan dan pengetahuan tentang pentingnya menjaga lingkungan.

Penyampaian sumber pencemar laut sifatnya edukatif sedangkan pelaksanaan aksi bersih atau upaya pengumpulan sampah di pesisir pantai bersifat persuasif. Artinya ingin mengajak masyarakat maupun wisatawan untuk menjaga kebersihan pantai sehingga pantai dapat terjaga kelestariannya. Realisasi dari kegiatan ini dapat dilihat dari indikator keberhasilan program yang disajikan pada Tabel 1.

Tabel 1 Indikator keberhasilan program

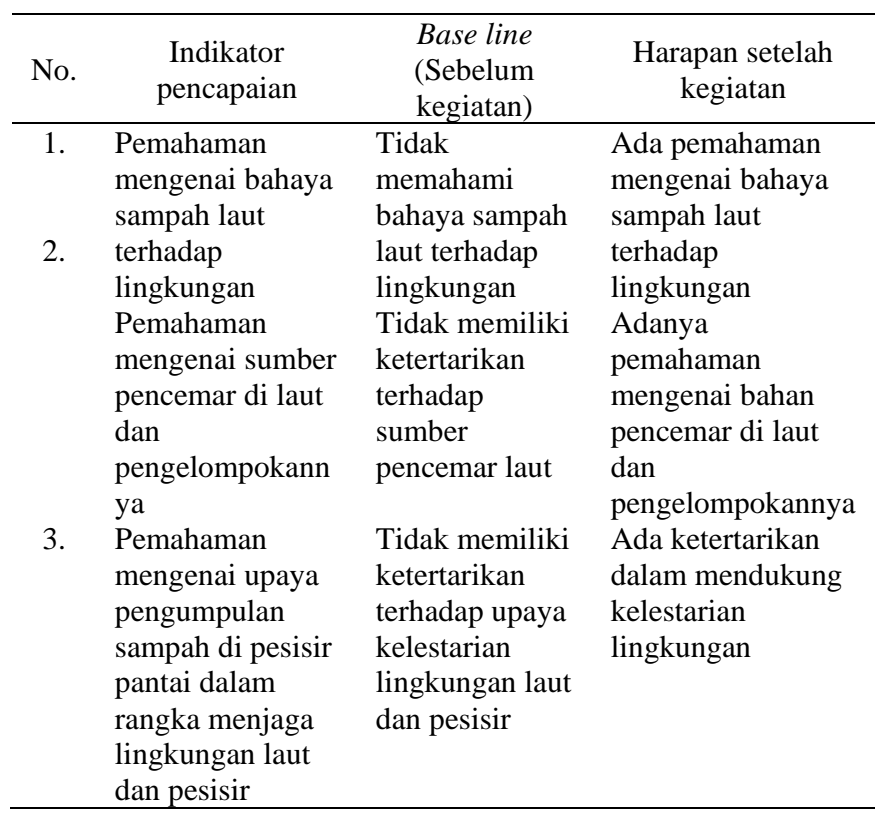

Kegiatan ini dilaksanakan selama bulan AgustusOktober 2017 di Pantai Pangandaran. Khalayak sasaran berupa warga/masyarakat yang tinggal di sekitar pantai serta wisatawan yang berkunjung di lokasi pantai Pangandaran. Pelaksanaan kegiatan dilakukan secara 3 tahap. Tahap pertama melakukan inisiasi kepada dinas dan lembaga setempat untuk melakukan perijinan kegiatan. Tahap kedua yaitu pelaksanaan kegiatan dengan memberikan pembekalan berupa pengetahuan bahan pencemar lingkungan pesisir khususnya laut. Dilanjutkan dengan mengajak khalayak sasaran bersama-sama dalam pengumpulan sampah di pesisir pantai Pangandaran. Tahap ketiga yaitu evaluasi kegiatan yang telah dilaksanakan. Tahap ini adalah bentuk diskusi antara pelaksana kegiatan dengan khalayak sasaran untuk memastikan bahwa khalayak sasaran dapat memahami pentingnya menjaga lingkungan pesisir pantai. Selain itu juga untuk mengetahui tingkat keberhasilan kegiatan dan dampaknya terhadap pola pikir khalayak sasaran.

\section{Hasil dan Pembahasan}

Kegiatan bersih pantai (coastal cleanup) ini merupakan bagian dari upaya warga dunia untuk perduli terhadap kebersihan lingkungan pesisir. Kegiatan ini bersifat internasional dan melibatkan para relawan untuk melakukan kegiatan bersih pantai dengan metode survey, biasanya dilakukan dalam periode yang bersamaan. Kegiatan ini dikenal pula dengan International Coastal Cleanup (ICC) yang dilakukan secara serentak di berbagai pesisir pantai di seluruh dunia. ICC merupakan konsep kegiatan yang efektif untuk meningkatkan kesadaran masyarakat terhadap pencemaran pesisir pantai melalui pengalaman langsung survey dan mengambil sampah secara langsung (Ohkura \& Kojima, 2007).

Pelaksanaan kegiatan diawali dengan tahap sosialisasi dan inisiasi kepada dinas dan lembaga setempat untuk melakukan perijinan kegiatan. Tahap ini disambut positif oleh pihak Dinas dan Kepala Desa Pananjung dengan mendukung dan mengijinkan berlangsungnya kegiatan ini. Kepala Desa mengatakan untuk siap mendukung segala bentuk kegiatan yang berkaitan dengan keleastarian lingkungan.

Pelaksanaan kegiatan diawali dengan tahap persiapan. Tahap persiapan mencakup tahap persiapan alat dan bahan yang digunakan dalam kegiatan ini. Alat dan bahan yang digunakan dalam kegiatan ini diantaranya timbangan digital, trash bag, logsheet (formulir ICC); Global Positioning System (GPS), roll meter, dan kamera. Jika alat dan bahan 
siap, maka tim PPM akan mendatangi sekelompok masyarakat maupun wisatawan yang ada di sekitar pantai untuk bersama-sama melakukan kegiatan aksi bersih pantai.

Masyarakat maupun wisatawan yang bersedia dilibatkan dalam kegiatan ini selanjutnya diberikan pengarahan. Pengarahan berupa diskusi mengenai pengetahuan berupa pentingnya mengetahui sumber pencemar di laut dan pengelompokannya serta bahaya sampah laut untuk lingkungan pesisir. Selain itu, khalayak sasaran juga ditunjukkan dengan bentuk pengelompokan sampah yang ditemukan di laut dan penjelasan mengenai formulir ICC. Berbagai pertanyaan dan pendapat dilontarkan oleh para khalayak sasaran sehingga suasana pertemuan terasa akrab dan semangat. Banyaknya pertanyaan dan lontaran pendapat tersebut menunjukkan bahwa materi yang disampaikan dapat dikatakan telah tersampaikan kepada objek sasaran dengan baik. Pemateri tidak banyak mengalami kesulitan dalam memberikan pengarahan pada khalayak sasaran. Diskusi dengan masyarakat maupun wisatawan ditunjukkan pada Gambar 1.
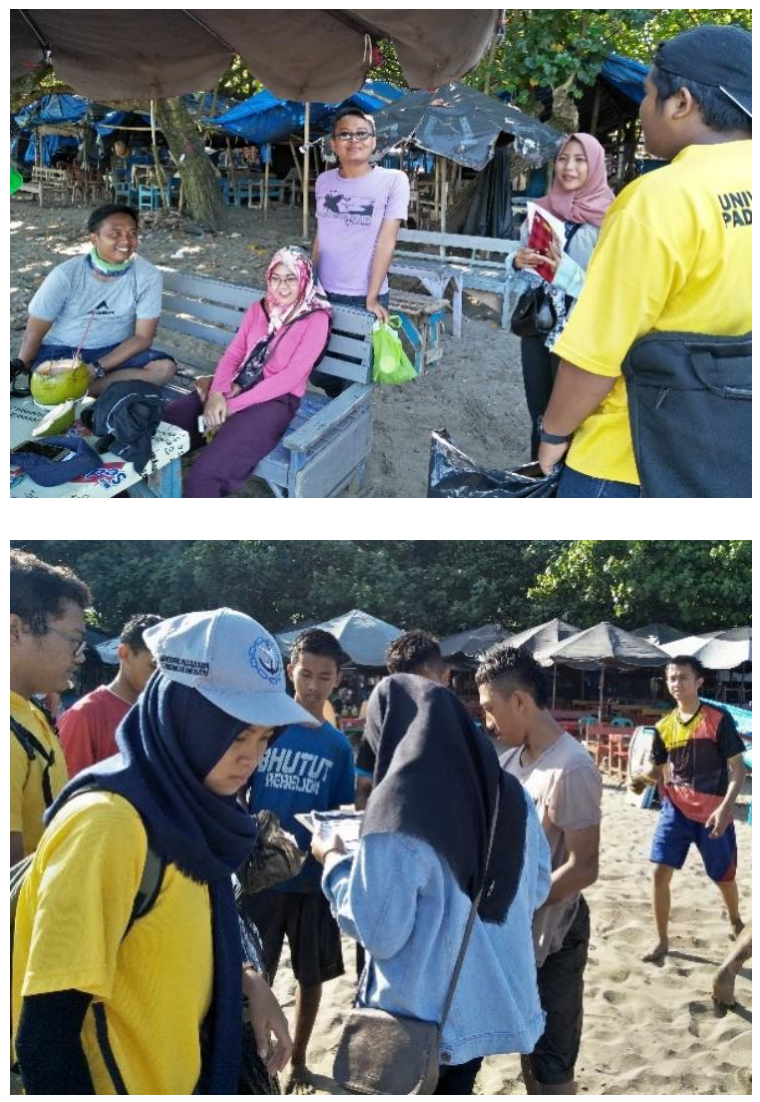

Gambar 1 Pengarahan dan diskusi dengan khalayak sasaran (kiri) arahan dengan peserta, (kanan) aksi pengumpulan sampah di pantai secara berkelompok
Kegiatan ini bertepatan dengan 60 tahun ulang tahun Universitas Padjadjaran sehingga tema "Unpad Bebersih Pantai" akan menjadi tema yang dibawa. Tema tersebut menjadi motivasi terhadap pelaksanaan PPM ini. Kegiatan selanjutnya para khalayak sasaran diarahkan untuk melakukan aksi bersih pantai dan mengelompokkan sampah sesuai dengan arahan yang ada pada formulir ICC. Kegiatan ini berjalan dengan baik para peserta khalayak sasaran dan tim PPM dalam melakukan aksi bersih pantai. Kegiatan berlangsung dapat dilihat pada Gambar 2.
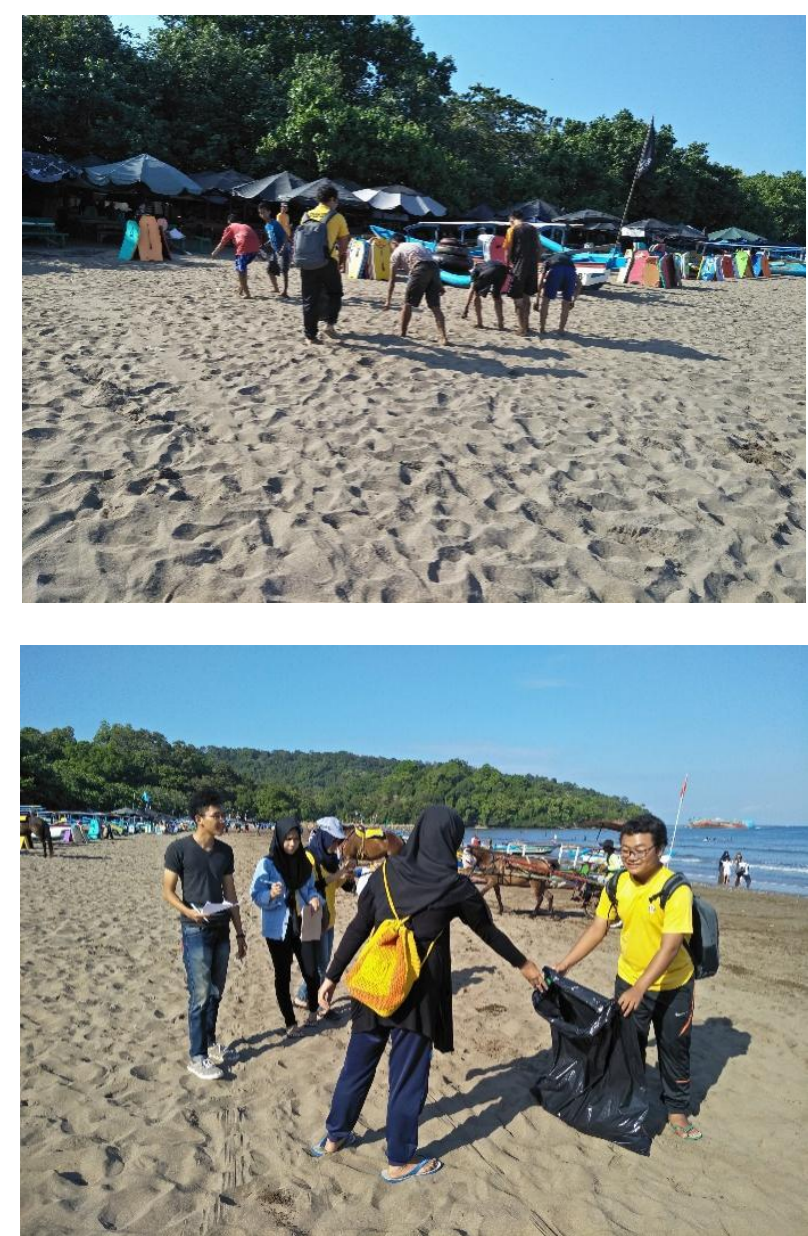

Gambar 2 Pelaksanaan kegiatan aksi bersih pantai yang dibagi menjadi beberapa group peserta

Akhir dari kegiatan ini yaitu berupa pengelompokkan sampah laut. Peserta khalayak sasaran terlihat antusias dalam pengelompokan sampah yang telah diarahkan sebelumnya. Pengisian formulir ICC juga dapat diselesaikan dengan baik oleh peserta dan tim PPM. Oleh karena itu, kegiatan ini tergolong mudah dilakukan oleh masyarakat maupun wisatawan. Diharapkan pemerintah maupaun pengelola wisata dapat melakukan kegiatan demikian secara rutin sebagai bentuk 
perlindungan terhadap lingkungan pesisir dan laut.

Secara umum kegiatan pelatihan pengumpulan sampah laut oleh pengunjung di Pantai Pangandaran berjalan dengan lancar. Berdasarkan Tabel 2 menunjukkan perubahan sudut pandang khalayak sasaran mengenai pentingnya menjaga kelestarian lingkungan laut.

Tabel 2 Indikator keberhasilan program

\begin{tabular}{|c|c|c|c|}
\hline No. & $\begin{array}{l}\text { Indikator } \\
\text { pencapaian }\end{array}$ & $\begin{array}{l}\text { Base line } \\
\text { (Sebelum } \\
\text { kegiatan) }\end{array}$ & $\begin{array}{c}\text { Pencapaian } \\
\text { setelah } \\
\text { kegiatan }\end{array}$ \\
\hline 1. & $\begin{array}{l}\text { Pemahaman } \\
\text { mengenai bahaya } \\
\text { sampah laut } \\
\text { terhadap } \\
\text { lingkungan }\end{array}$ & Belum memahami & $\begin{array}{l}\text { Ada } \\
\text { pemahaman }\end{array}$ \\
\hline 2. & $\begin{array}{l}\text { Pemahaman } \\
\text { mengenai sumber } \\
\text { pencemar di laut } \\
\text { dan } \\
\text { pengelompokannya }\end{array}$ & $\begin{array}{l}\text { Belum memahami } \\
\text { dan tidak } \\
\text { memiliki } \\
\text { ketertarikan }\end{array}$ & $\begin{array}{l}\text { Adanya } \\
\text { pemahaman }\end{array}$ \\
\hline 3. & $\begin{array}{l}\text { Pemahaman } \\
\text { mengenai upaya } \\
\text { pengumpulan } \\
\text { sampah di pesisir } \\
\text { pantai dalam } \\
\text { rangka menjaga } \\
\text { lingkungan laut dan } \\
\text { pesisir }\end{array}$ & $\begin{array}{l}\text { Tidak memiliki } \\
\text { ketertarikan }\end{array}$ & $\begin{array}{l}\text { Ada } \\
\text { ketertarikan }\end{array}$ \\
\hline 4. & $\begin{array}{l}\text { Pemahaman } \\
\text { terhadap form ICC }\end{array}$ & $\begin{array}{l}\text { Tidak mengetahui } \\
\text { Teknik } \\
\text { penggumpulan } \\
\text { data }\end{array}$ & $\begin{array}{l}\text { Mengetahui } \\
\text { Teknik dan } \\
\text { metode }\end{array}$ \\
\hline
\end{tabular}

\section{Kesimpulan}

Berdasarkan kegiatan pelatihan secara keseluruhan, baik dalam bentuk ceramah/diskusi maupun aksi bersih pantai dapat disimpulkan bahwa khalayak sasaran memahami pentingnya menjaga lingkungan pesisir dan laut. Serta adanya peningkatan skill khalayak sasaran dalam memahami form ICC dengan pengelompokkan sampah yang ada di dalamnya.

\section{Ucapan Terimakasih}

Penulis mengucapkan terima kasih kepada Direktorat Riset, Pengabdian Pada Masyarakat dan Inovasi Universitas Padjadjaran yang telah memberikan dana hibah Pengabdian Pada Masyarakat (PPM) Prioritas Multi Tahun tahun anggaran 2017. Ucapan terimakasih juga disampaikan kepada Kepala Desa, Ketua RW dan
RT serta masyarakat di Desa Pananjung Kabupaten Pangandaran khususnya disekitar Pantai Barat Pangandaran, serta mahasiswa Program Studi Perikanan PSDKU Unpad Pangandaran sehingga program pengabdian ini dapat terlaksana dengan baik.

\section{Daftar Pustaka}

Apriliani IM, Purba NP, Dewanti LP, Herawati H, Faizal I. 2017. Aksi Bersih Pantai dalam Rangka Penanggulangan Pencemaran Pesisir di Pantai Pangandaran. Jurnal Pengabdian Kepada Masyarakat 1(2): 77-80.

Darwati S. 2019. Pengelolaan Sampah Kawasan Pantai. Prosiding Seminar Nasional Pendidikan Biologi dan Saintek (SNPBS) ke-IV, 417-426.

Hiwari H, Purba NP, Ihsan YN, Yuliadi LPS, Mulyani PG. 2019. Condition of Microplastic Garbage in Sea Surface Water at around Kupang and Rote, East Nusa Tenggara Province. Prosiding Seminar Nasional Masyarakat Biodiversitas Indonesia 5(2): 165-171.

Hutabarat S, Evans SM. 1985. Pengantar Oseanografi. Jakarta (ID): UI Press.

Maharani A, Purba NP, Faizal I. 2018. Occurrence of beach debris in Tunda Island, Banten, Indonesia. E3S Web Conf. 47, 04006. https://doi.org/10.1051/e3sconf/20184704006

Ohkura Y, Kojima A. 2007. International Coastal Cleanup Campaign Coordinated by JEAN in Japan Present state and future prospects. The 2nd NOWPAP Workshop on Marine Litter. 28-29 March.

Pangestu IF, Purba NP, Syamsudin ML. 2016. Kondisi mikroplastik di Perairan Indramayu, Jawa Barat. Prosiding Seminar Nasional Perikanan dan Kelautan : Sinergitas Teknologi, Hukum, dan Kebijakan Bidang Perikanan dan Ilmu Kelautan Menuju Kedaulatan Pangan di Era MEA (Bandung, Indonesia), 382-390.

Pemda Kabupaten Pangandaran. 2016. Rencana Program Investasi Jangka Menengah (RPIJM) Bidang Cipta Karya 2016-2020. Pangandaran : Pemerintah Daerah Kabupaten Pangandaran.

Purba NP, Apriliani IM, Dewanti LP, Herawati H, Faizal I. 2018. Distribution of Macro Debris at Pangandaran Beach, Indonesia. World Scientific News 103: 144-156. 
Apriliani et al (2021) FJCS 02(1): $56-61$

Purba NP, Syamsuddin ML, Sandro R, Pangestu IF, Prasetio MR. 2017. Distribution of Marine Debris in Biawak Island, West Java, Indonesia. World Scientific News 66: 281-292.

Rachmat SLJ, Purba NP, Agung MUK, Yuliadi LPS. 2019. Characteristics of Microplastics at Jakarta Estuaries. Depik 8(1): 1-10.

Saimama IDS, Noviansyah. 2020. Model Persuasif Edukatif Bagi Masyarakat untuk Mendukung Program Asimilasi dan Integrasi Bagi Narapidana Anak pada Masa Pandemi Covid19. Res Judicata 3(1): 51-65. 